\title{
Enhanced Saccharification in Sugarcane Leaves by Combined Pretreatment of Ionic Liquid and Aqueous Ammonia
}

\author{
Archana Singh, Ashutosh Dubey, Vivek Chandra Verma, \\ Brijesh Lekhak and A.K. Verma*
}

Department of Biochemistry, College of Basic Sciences and Humanities, G. B. Pant University

of Agriculture and Technology, Pantanagar, Uttarakhand, India

*Corresponding author

\section{A B S T R A C T}

\begin{tabular}{|l|}
\hline K e y w o r d s \\
Lignocellulose, \\
$\begin{array}{l}\text { Pretreatment, } \\
\text { Saccharification, Ionic } \\
\text { liquid, Biodigestibility, } \\
\text { Biofuel }\end{array}$ \\
\hline Article Info \\
\hline $\begin{array}{l}\text { Accepted: } \\
\text { 26 April 2018 } \\
\text { Available Online: } \\
\text { 10 May 2018 }\end{array}$ \\
\hline
\end{tabular}

Total recovery of fermentable sugar from lignocellulosic biomass has foremost problem for liquid biofuel production. Several pretreatment methods have been tried, however use of ionic liquids is one of promising method then others, but it also has less efficiency. Hence a method was developed for pretreatment of sugarcane leaves using ionic liquid EmimAc (1-ethyl-3-methylimidazolium acetate), aqueous ammonia and a combination of both. The combined use of ionic liquid and aqueous ammonia in 1:1 for pretreatment at 6 hrs followed by cellulase treatment showed a synergistic effect on sugarcane leaves with release of $90 \%$ glucose. While pretreatment with ionic liquid alone and aqueous ammonia alone followed by cellulase treatment produced $70 \%$ and $45 \%$ of glucose respectively. The ionic liquid was successfully recycled to minimize the cost, up to 6 times with efficiency of $87 \%$ release of glucose. Compared with the conventional pretreatment and other methods, this combined method is more efficient and cost effective.

\section{Introduction}

Lignocellulosic biomass is an abundant and promising biofuel resource that can substitute fossil fuels (Li et al., 2010). This resource contains large amounts of cellulose and hemicelluloses that can produced alternative fuel via saccharification and fermentation thereby alleviating dependency on conventional fuel (Behera et al., 2014). Due to complexity and variability in various lignocellulosic biomass the pretreatment methods may also be vary. Chemical pretreatment methods are always been required for the accessibility of lignocelluloses substrate for its hydrolyzing enzymes. However the product of the pretreatments inhibited the enzymatic action (Chang and Holtzapple, 2000). There are several pretreatment techniques have been proposed such as physical, chemical, biological and physico-chemical treatments like grinding and milling, hot water (Cara et al., 2007), acidic, alkali and biological pretreatment (Perez et al., 2008; Taherzadeh et al., 2008; Kumar et al., 2009). Though, there are a number of problems associated with these methods such as severe reaction conditions, requirement of high energy, toxicity and expensive operation (Balat et al., 2011). Additional drawbacks of 
acid and chemical pretreatments are that it is hazardous, do not effectively remove lignin and involvement of corrosive resistant material and added recover process. Ammonia fiber explosion, liquid hot water and steam explosion pretreatment have a great potential, but required either high pressure or high temperature environment (Mosier et al., 2005). Furthermore, the price of these above techniques has been much higher than the value of the product that is glucose. This principally causes notable economical drawbacks (Teymouri et al., 2005). Recently, the use of ionic liquids (ILs) for pretreatment of lignocellulosic biomass has provided significant scope. IL has considered being very efficient in removing lignin and also helping in reducing cellulose crystallinity (Lee et al., 2009, Li et al., 2010). Furthermore, IL pretreatment can be dissolved a variety of lignocellulosic biomasses such as softwood, hardwood and herbaceous resources (Nguyen et al., 2010; Sun et al., 2009). The lignocellulosic biomass pretreatment with IL can provide a number of attractive features when compared to conventional techniques (Li et al., 2008). These contain the potential for considerably lower temperature below $100^{\circ} \mathrm{C}$ and less hazardous conditions. Furthermore, IL can be reused and can easily improve the enzyme accessibility and efficiently to produce fermentable sugars like glucose and xylose from lignocellulosic biomass (Swatloski et al., 2002 and Zhang et al., 2005). Although pretreatment with IL has been increased interest as a new technology since past few years, this technique has been too costly in application for lignocellulosic biomass pretreatment due to the high price of IL. Consequently, advanced technology with IL is requisite to make the technique further efficient while lowering the price (Kim and Lee 2007).

Worldwide sugarcane production approximates 1.83 billion tons. In India it is estimated to 352.14 million tons which produces 6-8 tons of dried leaves per hectare. That is a huge amount biomass for ethanol production. Hence it is essential to develop the pretreatment technology for saccharification of sugarcane leaves. In this paper, a systematic study on pretreatment of sugarcane leaves using a combination of aqueous ammonia and IL, IL alone and aqueous ammonia alone were taken with the principle of making an efficient technique for lignocelluloses biomass pretreatment. Aqueous ammonia was used as one of the most helpful chemical to eliminate lignin from lignocellulosic biomass (Murnen et al., 2007, Wyman et al., 2005). Aqueous ammonia can generally react by lignin can cause delignification by disrupting lignincarbohydrate association under elevated temperature (Chang et al., 2001).

This combined system has been depends on delignification outcome of ammonia (Wyman et al., 2005) and cellulose solubilization by IL (Swatloski et al., 2002) to increase biodigestibility of lignocellulosic biomass for enzymatic action and the reutilization of IL for charge minimization. In this study, commercial cellulase was used to hydrolyze pretreated substrate. The ionic liquid 1-nethyl-3-methyl imidazolium acetate EmimOAc, was taken due to its low viscosity and low melting temperature that leading easy handling and imidazolium group is substituted by relatively short alkyl chain, IL with shorter alkyl chains has been found to be less toxic (Romero et al., 2008). Furthermore, the acetate anion makes the IL less corrosive than IL with halide anion that also has been useful in cellulose dissolution.

\section{Materials and Methods}

\section{Biomass}

Sugarcane leaves were obtained from crop research center, Pantnagar. Sugarcane leaves 
were dried in air, chopped in to three different sizes viz. $<2 \mathrm{~mm}, 2-5 \mathrm{~mm}$ and $5-10 \mathrm{~mm}$ and stored at ambient temperature for further study.

\section{Proximate analysis}

Sugarcane leaves were analyzed for cellulose, hemicelluloses and lignin contents by using the method given by Aravantinos-Zafiris et al., 1994 and Ververis et al., 2007. Sugarcane leaves $(700 \mathrm{mg}$ ) boiled in $5 \mathrm{ml}$ of $70 \% \mathrm{w} / \mathrm{w}$ $\mathrm{H}_{2} \mathrm{SO}_{4}$ solution for $4 \mathrm{hrs}$ in order to hydrolyze hemicellulose and cellulose. The solid residue dried at $100^{\circ} \mathrm{C}$ for $24 \mathrm{hrs}$ and weighed (W1). The residue was heated at $100^{\circ} \mathrm{C}$ for $24 \mathrm{hrs}$, after cooling down it was weighed (W2) and lignin content was calculated by the difference (W1 - W2). The filtrate contained the sugar released from hemicellulose and cellulose was determined. Glucose $(\mathrm{C} 1)$ and reducing sugars (C2) concentration in the filtrate were determined with a GOD-POD assay kit (M/S Autospan, Span Diagnostic Ltd) and DNS method (Miller et al., 1959) respectively. The cellulose content was calculated by using the following formula:

$\%$ w/w cellulose content $=(0.9 / 0.96) \times \mathrm{C} 1 \times$ (V/M) x $\alpha$ x100

Where,

0.9 is the coefficient and the saccharification yield is taken as 0.96 ,

C1 glucose concentration (g/L),

V total volume of sugar solution (L),

M dry weight of the sample (g) and,

$\alpha$ dilution of the sample (if any).

Hemicellulose content was calculated by following formula:
$\% \mathrm{w} / \mathrm{w}$ hemicelluloses $=(0.88 / 0.93) \times(\mathrm{C} 2-$ C1) $\mathrm{x}(\mathrm{V} / \mathrm{M}) \times \alpha \times 100$

Where,

0.88 is the coefficient,

0.93 saccharification yield,

C2 is reducing sugars concentration $(\mathrm{g} / \mathrm{L})$ by DNS method,

C1 glucose concentration (g/L) from above,

V total volume of sugar solution (L),

M dry weight of sugarcane leaves sample (g) and,

$\alpha$ dilution factor of the sample (if any).

\section{Ionic liquid pretreatment}

Chopped leaves $(50 \mathrm{mg})$ were pretreated with $1 \mathrm{ml}$ of IL, 1-ethyl 3-methyl imidazolium acetate (EmimOAc) purchased from sigmaAldrich and incubate in oven at $80^{\circ} \mathrm{C}$ for 6 hrs. After dissolution $5 \mathrm{ml}$ of ethanol used as an antisolvent was added into sugarcane leaves, to precipitate and regenerate the biomass-cellulose under vigorously stirring condition. The precipitated material was filtered through filter paper (Whatman no\#1) and washed with $5 \mathrm{ml}$ ethanol. The filtered liquid containing ILs and ethanol was recovered for subsequent reutilization after removing the antisolvent ethanol by evaporation. The precipitated material was continuously washed with distilled water and dried at $50^{\circ} \mathrm{C}$ for $3 \mathrm{hrs}$. The dried material was used for cellulase treatment.

\section{Aqueous ammonia pretreatment}

Sugarcane leaves $(50 \mathrm{mg})$ were mixed with 1 $\mathrm{ml}$ of $25 \%(\mathrm{v} / \mathrm{v})$ ammonia solution and 
incubated at $80^{\circ} \mathrm{C}$ for $6 \mathrm{hrs}$. The samples were washed with distilled water and filtered through filter paper (Whatman no. 1). The precipitated material was dried at $60^{\circ} \mathrm{C}$ for 3 hrs and used for cellulase treatment.

\section{Pretreatment with aqueous ammonia and} IL

Sugarcane leaves $(50 \mathrm{mg})$ mixed with $0.5 \mathrm{ml}$ of $25 \%(\mathrm{v} / \mathrm{v})$ ammonia solution and $0.5 \mathrm{ml} \mathrm{IL}$ and incubated at $80^{\circ} \mathrm{C}$ for $6 \mathrm{hrs}$. After drying, the sample was filtered through filter paper (Whatman no\#1) and washed with distilled water. The samples were dried in oven at $60^{\circ}$ $\mathrm{C}$ for $3 \mathrm{hrs}$ prior to cellulase treatment.

\section{Cellulolytic hydrolysis}

Commercial cellulase "ONOZUKA R-10", from Trichoderma viride (10U/mg) perchased from Hi-media was taken for enzymatic saccharification. Cellulase $(320 \mu \mathrm{g} / \mathrm{ml}$ in acetate buffer, $\mathrm{pH} 4.5$ ) solution of $1 \mathrm{ml}$ was mix with biomass (pretreated) and incubates at $40^{\circ} \mathrm{C}$ for $50 \mathrm{~min}$. The contents of glucose and reducing sugar in the enzymatic hydrolysed sample were determined by enzyme base glucose detection kit and DNS method (Miller et al., 1959), respectively.

\section{Scanning Electron Microscopy (SEM)}

Surface morphology of sugarcane leaves of both pretreated and un-pretreated (dried powder) were analysed under JEOL-JSM 6610ALV made in Japan gold coater JFC 1600 scanning electon microscope.

\section{FTIR spectroscopy}

Fourier transform infrared spectroscopy was done for both pretreated and untreated sugarcane leaves using BRUKER ALPHA ECO-ATR spectroscopy.

\section{Statistical analysis}

The data were analysed by ANOVA at $\mathrm{p}<0.05$ using STPR software.

\section{Results and Discussion}

\section{Proximate analysis}

Proximate analysis of lignin, cellulose and hemicelluloses contents for sugarcane leaves are shown in Table.1. The lignin content reduced two fold after IL pretreatment, while cellulose content increased two fold and simultaneously hemicelluloses content increased up to some extent.

Effect of particle size on release of reducing sugar and glucose

The criteria for successful pretreatment of lignocellulosic biomasses have been defined to enhanced cellulose recovery for the production of fermentable sugars by enzymatic (cellulase) hydrolysis and low lignin contents in pretreated biomasses in order to enhance the accessibility of cellulase enzyme for cellulose (Nguyen et al., 2010, Mosier et al., 2005). Based on these criteria, combined method by using synergistic effect of IL and aqueous ammonia was developed. In this combined reaction aqueous ammonia was applied as a supplementary step to increase the effectiveness of IL treatment and high temperature $\left(100^{\circ} \mathrm{C}\right)$ was used to achieve effective degradation of lignin. The size of sample particle was one of the essential parameter in lignocelluloses pretreatment because this factor directly force on the diffusion of chemical into complex internal of lignocellulosic material (Wyman et al., 2005). Untreated, IL, aqueous ammonia and combine $\mathrm{IL}$ and aqueous ammonia were analyzed with different sizes of particle viz. $<2 \mathrm{~mm}, 2-5 \mathrm{~mm}$, and 5-10 $\mathrm{mm}$ of sugarcane leaves samples. In this research, particle sizes were found to be 
an essential factor affecting on sample pretreatment. The outcome of these three different sizes of particles was shown in Fig. $1 \mathrm{a}$ and $1 \mathrm{~b}$. Reducing sugar and glucose production after enzymatic hydrolysis was noticeably different for these three techniques and was negligible in untreated. The particle size of $<2 \mathrm{~mm}$ illustrate the highest conversion of reducing sugar and glucose, conversion in 2-5 mm particle size sample was considerably higher than the 5-10 $\mathrm{mm}$ particle size. Comparison of these techniques tested on different particle size of sugarcane leaves samples, combined method of ammonia and IL was the most effective for conversion of cellulose into simple fermentable sugars.

Effect of pretreatment time in release of Reducing sugar and Glucose

The results of efficiency of aqueous ammonia, $\mathrm{IL}$ and combined aqueous ammonia and IL technique were tested on sample with particle size $<2 \mathrm{~mm}$ with different times of solubility viz. $3 \mathrm{hrs}, 6 \mathrm{hrs}$ and $9 \mathrm{hrs}$ were shown in Figure $2 \mathrm{a}$ and $2 \mathrm{~b}$. Use of IL and aqueous ammonia simultaneously showed higher contents of reducing sugar and glucose than in aqueous ammonia and IL alone at all time of solubility. This combined pretreatment found more efficient which gave the synergistic outcome of ILs and aqueous ammonia for sugarcane leaves pretreatment. Hence use of both IL and aqueous ammonia can curtail time of solubility. In aqueous ammonia and IL alone method, time required for solubility of lignocellulosic biomass was longer than combine method hence it showed low solubility at lower incubation time (Fort et al., 2007). In the combined method high reducing sugar and glucose conversion was showed even in less time of solubility at $6 \mathrm{hrs}$.

\section{Scanning electron microscopy analysis}

SEM images of untreated and IL pretreated were taken at 500x magnification. The results showed that the untreated sugarcane leaves have a high fibrillar and intact morphology (Fig. 4a). The major fibrillar cellulose structures are preserved and lignin carbohydrate complex may be condensed on cellulose fiber surface (Zhu et al., 2009). In comparison, IL pretreated sample has no intact or fibrous structure these observations consistent with higher rate of hydrolysis consequently high yield of glucose (Fig. 4b) (Gong et al., 2010, Tiwari et al., 2018).

Fig.1a Effect of particle size on release of reducing sugars from untreated and pretreated sugarcane leaves. Sugarcane leaves were pretreated with ammonia, ILs and both. The pretreated biomass was used for enzymatic hydrolysis

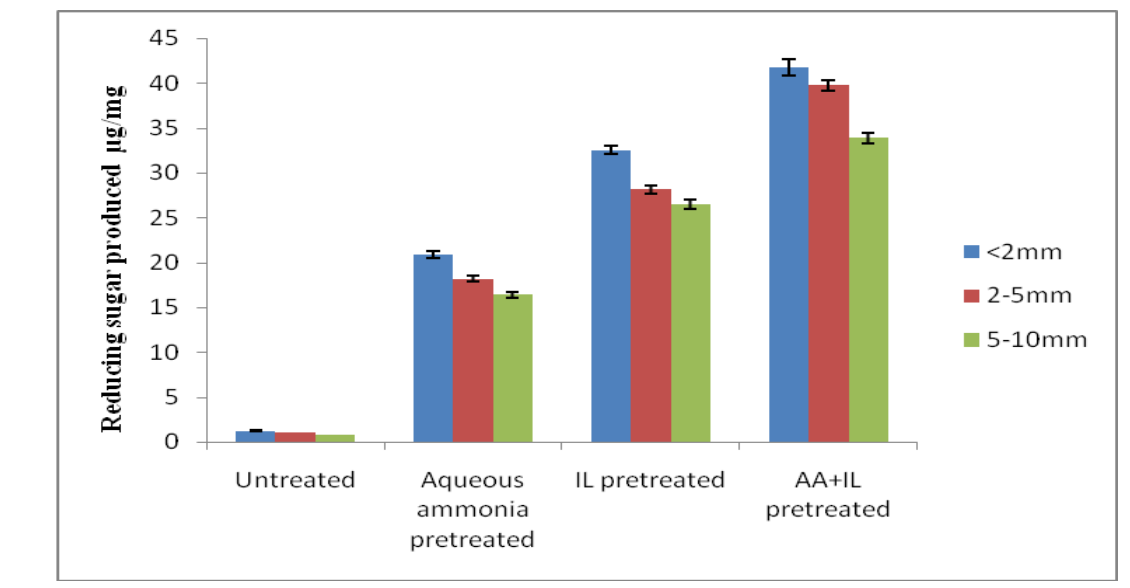

CD Value (2mm, 2-5mm. 5-10mm) 0.043, 0.038, 0.075 respectively 
Fig.1b Effect of particle size on release of glucose from untreated and pretreated sugarcane leaves. Sugarcane leaves were pretreated with aqueous ammonia, ILs and both. The pretreated biomass was used for enzymatic (cellulase) hydrolysis

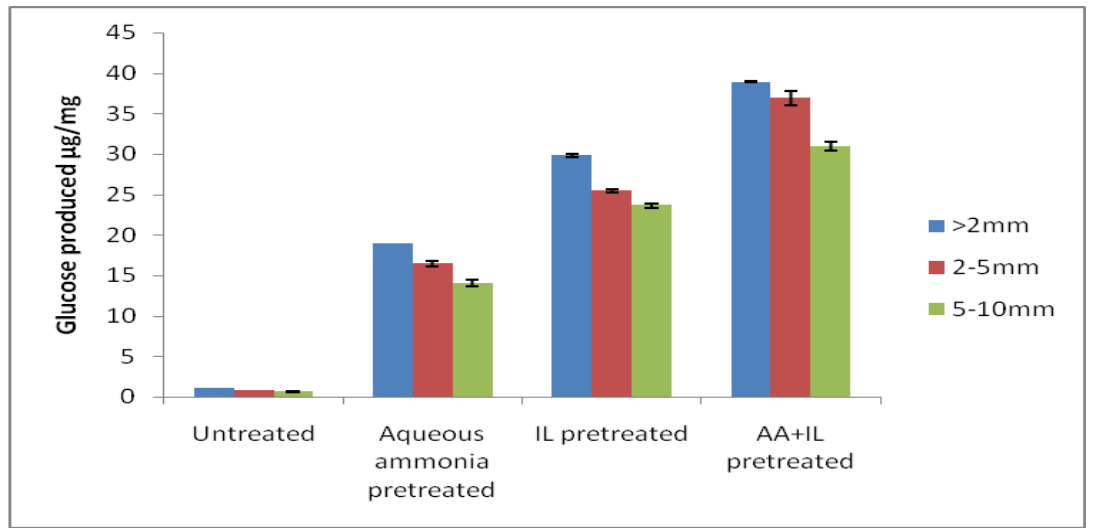

Fig.2a Effect of pretreatment time on release of reducing sugars from untreated and pretreated sugarcane leaves. Sugarcane leaves were pretreated with aqueous ammonia, IL and both. The pretreated biomass was used for enzymatic (cellulase) hydrolysis

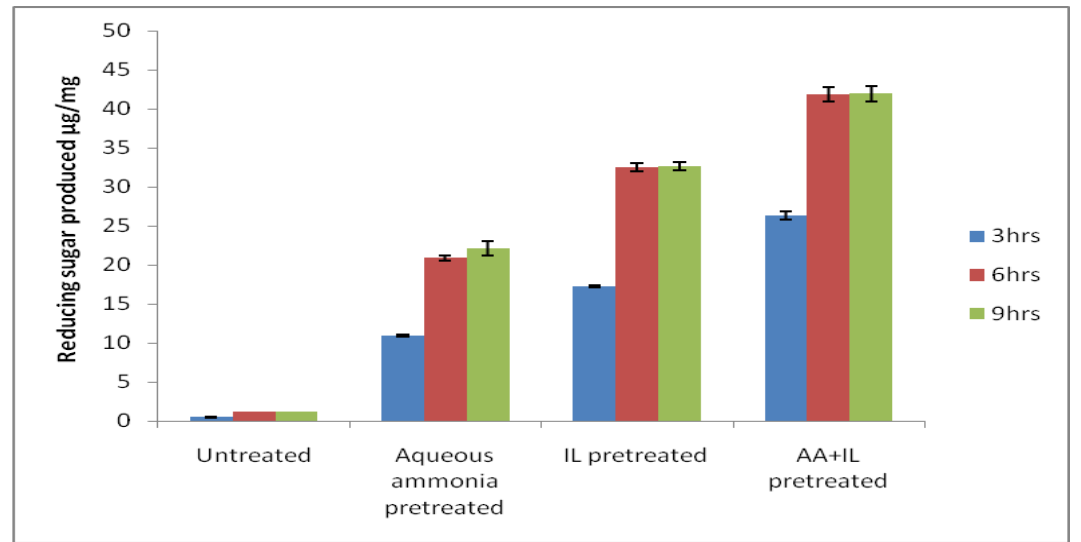

CD Value (3hrs, 6hrs, 9hrs) 0.013, 0.012, 0.023 respectively

Fig.2b Effect of pretreatment time on release of glucose from untreated and pretreated sugarcane leaves. Sugarcane leaves were pretreated with aqueous ammonia, IL and both. The pretreated biomass was used for enzymatic (cellulase) hydrolysis

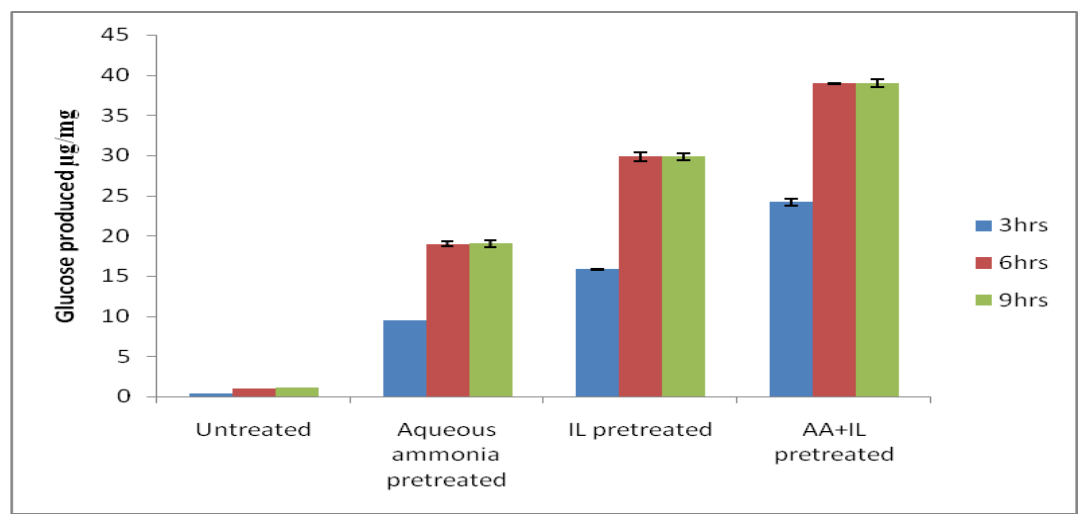

CD Value (3hrs, 6hrs, 9hrs) 0.005, 0.004, 0.008 respectively 
Fig.3a Comparison of recycling of IL alone and IL+aqueous ammonia combined pretreated sugarcane leaves on release of reducing sugar

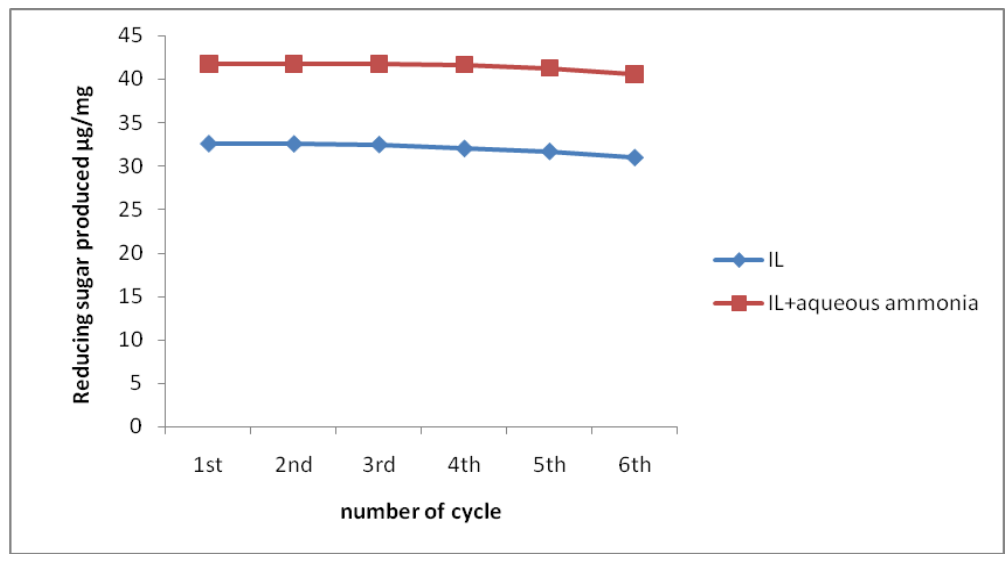

Fig.3b Comparison of recycling of IL alone and IL+aqueous ammonia combined pretreated sugarcane leaves on release of glucose

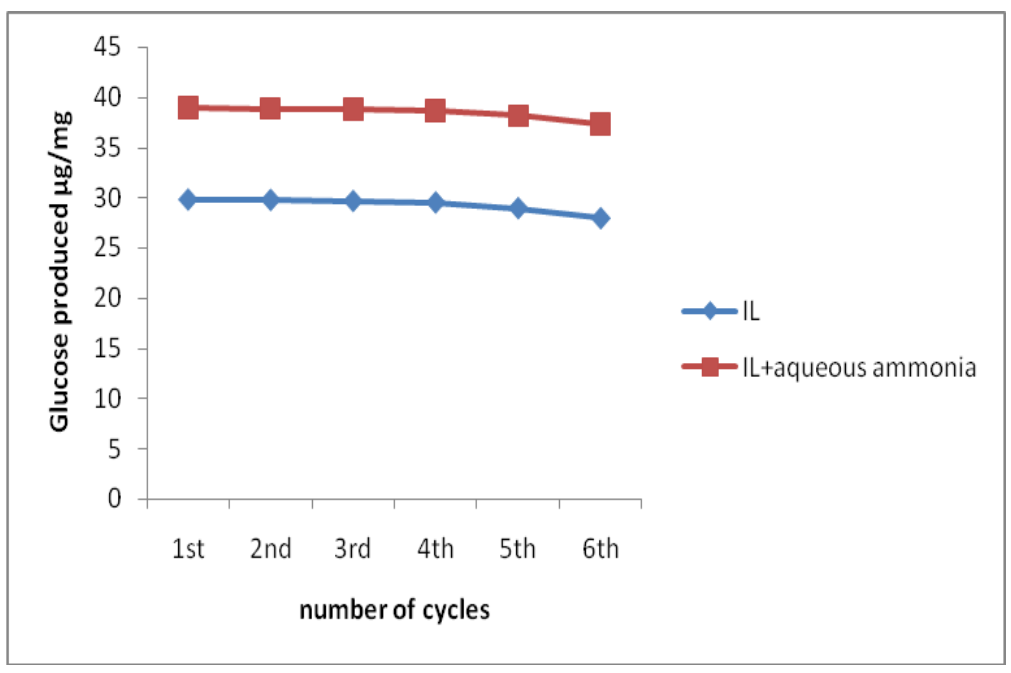

Fig.4a SEM image of untreated sugarcane leaves

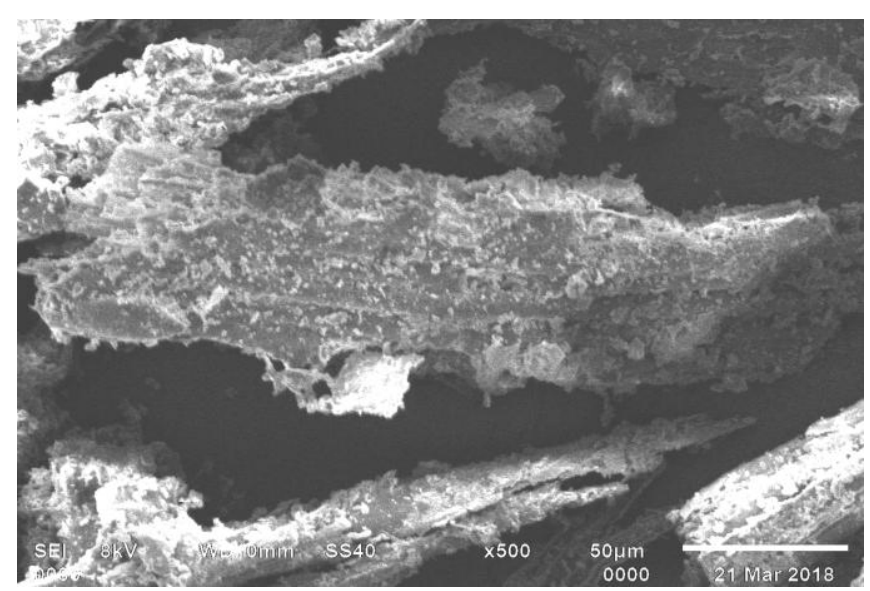


Fig.4b SEM image of IL pretreated sugarcane leaves

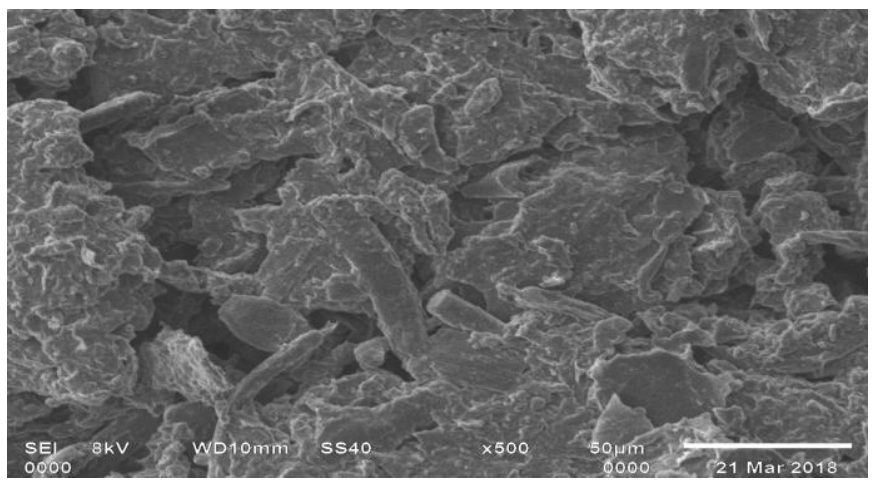

Fig.5 Fourier transform infrared (FTIR) spectral analysis of untreated (red) and ILs pretreated (pink) of sugarcane leaves

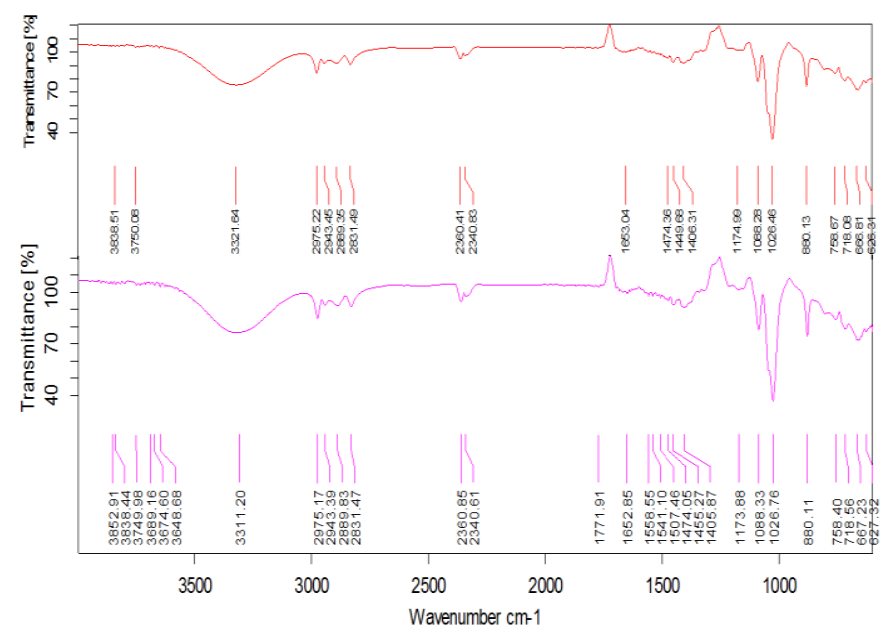

Table.1 Proximate analysis of sugarcane leaves before and after IL pretreatment

\begin{tabular}{|l|l|l|}
\hline Parameter & Before pretreatment (\%) & After IL pretreatment (\%) \\
\hline Cellulose & 20.09 & 43.71 \\
\hline Hemicelluloses & 14 & 18.35 \\
\hline Lignin & 12 & 6
\end{tabular}

\section{Fourior transform infrared FTIR analysis}

FTIR spectra of untreated and pretreated with IL of sugarcane leaves waste are shown in Figure 5. A deep peak at $1026 \mathrm{~cm}^{-1}$ in pretreated sugarcane leaves showed the presence of $\beta$-glycisidic bond of cellulose between sugar units (Tiwari et al., 2018). Additional peaks between $1405 \mathrm{~cm}^{-1}$ to 1771 $\mathrm{cm}^{-1}$ and $3500 \mathrm{~cm}^{-1}$ to $3852 \mathrm{~cm}^{-1}$ in pretreated sample indicated the removal of lignin and structural damage in lignocellulosic biomasses (Gong et al., 2010).

\section{Recycling of ILs}

An additional advantage of using IL is that, the potential recycling and reuses (Zhu et al., 
2012 and Hermanutz et al., 2008). In the current study, ILs was recycled for 6 times in both, IL alone and IL-aqueous ammonia combination. The efficiency of pretreatment by using recycled IL was shown in Fig.3a and Fig.3b. The reducing sugar and glucose conversion slightly declined as recycling and reusing was done in both methods.

Though the conversion of reducing sugar and glucose in combined method was clearly higher than IL alone method. Up to the $4^{\text {th }}$ cycle, it showed similar glucose conversion comparative to first $(90 \%$ for combine method and $70 \%$ for IL alone method) cycle. Even with $6^{\text {th }}$ cycle the conversion in combined treatment and IL alone showed $87 \%$ and $65 \%$ respectively. As a result, the combine method of IL and aqueous ammonia has improved number of recycling of IL in pretreatment technology.

There are various pretreatment methods for utilization of lignocellulosic materials (Wyman et al., 2005). In recent years IL has been utilized as new solvents for pretreatment of lignocellulosic materials. This study showed a promising combined method for sugarcane leaves waste pretreatment with aqueous ammonia and IL. Combined pretreatment method showed, reducing sugar and glucose conversion notably higher than IL and aqueous ammonia alone pretreatment. Regardless of its usefulness, usage of pretreatment with IL has been restricted because of high cost. The application of this combine method could remarkably reduce the solubility time of biomasses and increase the recycling number of IL solvents therefore cost minimization.

\section{Acknowledgement}

The authors are thankful to DST-FIST for providing equipment facility and the Directorate of Experiment Station (DES), Pantnagar, for utilization of infrastructure.

\section{References}

Aravantinos- Zafiris, G., Tzia, C., Oreopoulou, V. and Thomopoulos, C. D. 1994. Fermentation of orange processing wastes for citric acid production. Journal of the Science of Food and Agriculture. 65(1): 117-120.

Balat, M., 2011. Production of bioethanol from lignocellulosic materials via the biochemical pathway: a review. Energy conversion and management. 52(2): 858-875.

Behera, S., Arora, R., Nandhagopal, N. and Kumar, S. 2014. Importance of chemical pretreatment for bioconversion of lignocellulosic biomass. Renewable and Sustainable Energy Reviews. 36: 91-106.

Cara, C., Moya, M., Ballesteros, I., Negro, M. J., González, A. and Ruiz, E. 2007. Influence of solid loading on enzymatic hydrolysis of steam exploded or liquid hot water pretreated olive tree biomass. Process Biochemistry. 42(6): 10031009.

Chang, V. S., and Holtzapple, M. T. 2000. Fundamental factors affecting biomass enzymatic reactivity. Applied biochemistry and biotechnology. 84(1): 5-37.

Chang, V. S., Kaar, W. E., Burr, B. and Holtzapple, M. T. 2001. Simultaneous saccharification and fermentation of lime-treated biomass. Biotechnology Letters. 23(16): 1327-1333.

Fort, D. A., Remsing, R. C., Swatloski, R. P., Moyna, P., Moyna, G. and Rogers, R. D. 2007. Can ionic liquids dissolve wood? Processing and analysis of lignocellulosic materials with 1-n-butyl3-methylimidazolium chloride. Green Chemistry. 9(1): 63-69.

Gong, G., Liu, D. and Huang, Y. 2010. Microwave-assisted organic acid pretreatment for enzymatic hydrolysis 
of rice straw. Biosystems engineering. 107(2): 67-73.

Hermanutz, F., Gähr, F., Uerdingen, E., Meister, F. and Kosan, B. 2008. New developments in dissolving and processing of cellulose in ionic liquids. In Macromolecular symposia. 262(1): 23-27.

Kim, T. H. and Lee, Y. Y. 2007. Pretreatment of corn stover by soaking in aqueous ammonia at moderate temperatures. In Applied Biochemistry and Biotechnology. pp. 81-92. Humana Press.

Kumar, P., Barrett, D. M., Delwiche, M. J. and Stroeve, P. 2009. Methods for pretreatment of lignocellulosic biomass for efficient hydrolysis and biofuel production. Industrial \& engineering chemistry research. 48(8): 3713-3729.

Lee, S. H., Doherty, T. V., Linhardt, R. J. and Dordick, J. S. 2009. Ionic liquid- mediated selective extraction of lignin from wood leading to enhanced enzymatic cellulose hydrolysis. Biotechnology and Bioengineering. 102(5): 1368-1376.

Li, C., Knierim, B., Manisseri, C., Arora, R., Scheller, H. V., Auer, M. and Singh, S. 2010. Comparison of dilute acid and ionic liquid pretreatment of switchgrass: biomass recalcitrance, delignification and enzymatic saccharification. Bioresource technology. 101(13): 49004906.

Li, C., Wang, Q. and Zhao, Z. K. 2008. Acid in ionic liquid: An efficient system for hydrolysis of lignocellulose. Green Chemistry. 10(2): 177-182.

Miller, G. L. 1959. Use of dinitrosalicylic acid reagent for determination of reducing sugar. Analytical chemistry. 31(3): 426-428.

Mosier, N., Wyman, C., Dale, B., Elander, R., Lee, Y. Y., Holtzapple, M. and Ladisch, M. 2005. Features of promising technologies for pretreatment of lignocellulosic biomass. Bioresource technology. 96(6): 673-686.

Murnen, H. K., Balan, V., Chundawat, S. P., Bals, B., Sousa, L. D. C., and Dale, B. E. 2007. Optimization of ammonia fiber expansion (AFEX) pretreatment and enzymatic hydrolysis of Miscanthus $\mathrm{x}$ giganteus to fermentable sugars. Biotechnology progress. 23(4): 846850.

Nguyen, T. A. D., Kim, K. R., Han, S. J., Cho, H. Y., Kim, J. W., Park, S. M. and Sim, S. J. 2010. Pretreatment of rice straw with ammonia and ionic liquid for lignocellulose conversion to fermentable sugars. Bioresource technology. 101(19): 7432-7438.

Pérez, J. A., Ballesteros, I., Ballesteros, M., Sáez, F., Negro, M. J., and Manzanares, P. 2008. Optimizing liquid hot water pretreatment conditions to enhance sugar recovery from wheat straw for fuel-ethanol production. Fuel. 87(1718): 3640-3647.

Romero, A., Santos, A., Tojo, J. and Rodriguez, A. 2008. Toxicity and biodegradability of imidazolium ionic liquids. Journal of Hazardous Materials. 151(1): 268-273.

Sun, N., Rahman, M., Qin, Y., Maxim, M. L., Rodríguez, H. and Rogers, R. D. 2009. Complete dissolution and partial delignification of wood in the ionic liquid 1-ethyl-3-methylimidazolium acetate. Green Chemistry. 11(5): 646655.

Swatloski, R. P., Spear, S. K., Holbrey, J. D., \& Rogers, R. D. (2002). Dissolution of cellose with ionic liquids. Journal of the American chemical society. 124(18): 4974-4975.

Taherzadeh, M. J., and Karimi, K. 2008. Pretreatment of lignocellulosic wastes to improve ethanol and biogas production: a review. International 
journal of molecular sciences. 9(9): 1621-1651.

Teymouri, F., Laureano-Perez, L., Alizadeh, H., and Dale, B. E. 2005. Optimization of the ammonia fiber explosion (AFEX) treatment parameters for enzymatic hydrolysis of corn stover. Bioresource technology. 96(18): 2014-2018.

Tiwari, G., Sharma, A., Kumar, A. and Sharma, S. 2018. Assessment of microwave-assisted alkali pretreatment for the production of sugars from banana fruit peel waste. Biofuels. pp. 18.

Ververis, C., Georghiou, K., Danielidis, D., Hatzinikolaou, D. G., Santas, P., Santas, R. and Corleti, V. 2007. Cellulose, hemicelluloses, lignin and ash content of some organic materials and their suitability for use as paper pulp supplements. Bioresource Technology. 98(2): 296-301.

Wyman, C. E., Dale, B. E., Elander, R. T., Holtzapple, M., Ladisch, M. R. and Lee, Y. Y. 2005. Coordinated development of leading biomass pretreatment technologies. Bioresource technology. 96(18): 1959-1966.

Zhang, H., Wu, J., Zhang, J., and He, J. 2005. 1-Allyl-3-methylimidazolium chloride room temperature ionic liquid: a new and powerful nonderivatizing solvent for cellulose. Macromolecules. 38(20): 8272-8277.

Zhu, P., Chen, Y., Wang, L. Y. and Zhou, M. 2012. Treatment of waste printed circuit board by green solvent using ionic liquid. Waste management. 32(10): 1914-1918.

\section{How to cite this article:}

Archana Singh, Ashutosh Dubey, Vivek Chandra Verma, Brijesh Lekhak and Verma, A.K. 2018. Enhanced Saccharification in Sugarcane Leaves by Combined Pretreatment of Ionic Liquid and Aqueous Ammonia. Int.J.Curr.Microbiol.App.Sci. 7(05): 3522-3532. doi: https://doi.org/10.20546/ijcmas.2018.705.407 